\title{
Neuroinflammation and tumor necrosis factor signaling in the pathophysiology of Alzheimer's disease
}

Fiona E McAlpine

Malú G Tansey
Correspondence: Malú G Tansey

Department of Physiology, The University of Texas Southwestern Medical Center at Dallas, Dallas, Texas 75390, USA

Tel + I 2I4 6456037

Fax +I 2146456049

Email malu.tansey@utsouthwestern.edu
Abstract: Alzheimer's disease (AD) is a progressive neurodegenerative disorder that affects nearly one in two individuals over 90 years of age. Its neuropathological hallmarks are accumulation of extraneuronal plaques of amyloid-beta $(A \beta)$, the presence of neurofibrillary tangles formed by aberrantly hyperphosphorylated tau, progressive synaptic loss, and neurodegeneration which eventually results in decline of memory and cognitive faculties. Although the etiology of sporadic $\mathrm{AD}$ in humans is unknown, mutations in amyloid precursor protein or components of its processing machinery ( $\beta$-secretase and $\gamma$-secretase) result in overproduction of $A \beta 1-40$ and 1-42 peptides and are sufficient to cause disease. In this review, we highlight the experimental and clinical evidence that suggests a close association between neuroinflammation and AD pathogenesis. Overproduction of inflammatory mediators in the brain occurs when microglia, which are often found in close physical association with amyloid plaques in AD brains, become chronically activated. It has been proposed that elevated levels of pro-inflammatory cytokines, including tumor necrosis factor (TNF), may inhibit phagocytosis of $\mathrm{A} \beta$ in $\mathrm{AD}$ brains thereby hindering efficient plaque removal by resident microglia. In support of this idea, the bacterial endotoxin lipopolysaccharide, a potent trigger of inflammation that elicits production of TNF and many other cytokines, can accelerate the appearance and severity of AD pathology in several animal models of AD. We review the evidence implicating TNF signaling in AD pathology and discuss how TNF-dependent processes may contribute to cognitive dysfunction and accelerated progression of $\mathrm{AD}$. We conclude by reviewing the observations that provide compelling rationale to investigate the extent to which new therapeutic approaches that selectively target the TNF pathway modify progression of neuropathology in pre-clinical models of AD as well as the promising findings with the use of nonsteroidal anti-inflammatory drugs and recent clinical trials with $A \beta$ immunotherapy.

Keywords: neuroinflammation, tumor necrosis factor, microglia, neurodegeneration, Alzheimer's disease

\section{Introduction}

Alzheimer's disease (AD) is a progressive neurodegenerative disorder that affects nearly one in two individuals over 90 years of age (Kukull et al 2002). Its neuropathological hallmarks are accumulation of extraneuronal plaques of amyloid-beta $(A \beta)$ and the presence of neurofibrillary tangles formed by aberrantly hyperphosphorylated tau (Tanzi and Bertram 2005); progressive synaptic loss and neurodegeneration eventually result in decline of memory and cognitive faculties (reviewed in Wisniewski and Wegiel 1995). Although the etiology of sporadic AD in humans is unknown, mutations in amyloid precursor protein (APP) or components of its processing machinery ( $\beta$-secretase and $\gamma$-secretase) result in overproduction of $A \beta 1-40$ and $1-42$ peptides and are sufficient to cause disease (Nee et al 1983; Goate et al 1991; Citron et al 1992; Cai et al 1993; Lemere et al 1996; Lopera et al 1997; Whalen et al 2005). 
In this review, we highlight the experimental and clinical evidence that suggests a close association between neuroinflammation and AD pathogenesis (Akiyama et al 2000). Overproduction of inflammatory mediators in the brain occurs when microglia, which are often found in close physical association with amyloid plaques in AD brains (McGeer et al 1987), become chronically activated. It has been proposed that elevated levels of pro-inflammatory cytokines, including tumor necrosis factor (TNF), may inhibit phagocytosis of $\mathrm{A} \beta$ in $\mathrm{AD}$ brains thereby hindering efficient plaque removal by resident microglia (Koenigsknecht-Talboo and Landreth 2005). In support of this idea, the bacterial endotoxin lipopolysaccharide (LPS), a potent trigger of inflammation that elicits production of TNF and many other cytokines (Flick and Gifford 1986), can accelerate the appearance and severity of AD pathology in several animal models of AD (Qiao et al 2001; Sheng et al 2003), including the triple-transgenic $(3 \times \mathrm{TgAD})$ mouse (Kitazawa et al 2005), in which upregulation of TNF mRNA precedes the appearance of amyloid-associated pathology (Janelsins et al 2005) and correlates with cognitive deficits (Billings et al 2005). We also review the evidence implicating TNF signaling in AD pathology and discuss how TNF-dependent processes may contribute to cognitive dysfunction and accelerated progression of AD (Fillit et al 1991; Collins et al 2000; Paganelli et al 2002; Ma et al 2004; Tobinick et al 2006; Alvarez et al 2007; Tan et al 2007). We conclude by reviewing the observations that provide compelling rationale to investigate the extent to which new therapeutic approaches that selectively target the TNF pathway modify progression of neuropathology in preclinical models of AD as well as the promising findings with the use of nonsteroidal anti-inflammatory drugs (NSAIDs) and recent clinical trials with $A \beta$ immunotherapy.

\section{Neuropathological features of Alzheimer's disease}

Alzheimer's disease (AD) is a neurodegenerative disorder that affects a significant proportion of the elderly population. Its prevalence increases with age, with an estimated $4 \%$ of persons aged 65 to 74, rising to approximately $50 \%$ in persons 85 and above, diagnosed with AD (Evans 1990). It is the most common form of senile dementia, accounting for $70 \%$ of cases (Kawas et al 2000; Lobo et al 2000). In 2000 , there were an estimated 4.5 million patients with AD, and it is projected that that number will triple by 2050 as the population ages (Hebert et al 2003).

Alzheimer's disease was first described by Dr Alois Alzheimer in 1907, when he reported the case of a patient exhibiting memory loss and other cognitive impairments (see Alzheimer [1907], translated in Alzheimer and colleagues [1995]). He followed the patient until her death, and silver staining of her brain after autopsy revealed the hallmark pathological features of what is now known as Alzheimer's disease, plaques and tangles (Morris and Salmon 2007). Interestingly enough, brain tissue from Dr Alzheimer's first two patients has been found and reexamined, and both patients exhibit classical AD pathology and no signs of another cause for their dementia, confirming these early diagnoses (Graeber and Mehraein 1999). The psychological effects of AD are severe. Patients exhibit a progressive decline in several areas of cognition and memory. Most prominent is the loss of memory of events and people, but patients also show anomia (loss of the ability to name objects or persons), apraxia (loss of the ability to perform skilled or learned tasks), and other defects (Caselli et al 2006). The cognitive decline is accompanied by behavioral changes such as loss of inhibitions, delusions, agitation and aggressive behavior, depression and sleeping disorders (Caselli et al 2006; Rathmann and Conner 2007). AD is a devastating disease, not just for the patients, but also for their caregivers, who have a high probability of developing psychological problems and ill health (Pinquart and Sorensen 2003). Patients usually succumb to a concomitant infection or another chronic disease (Rathmann and Conner 2007). In recent years, mild cognitive impairment (MCI) has been identified as a precursor to AD. Patients with MCI perform in cognitive tasks at a level intermediate between healthy patients and AD patients, allowing clear identification of this population of pre-demented individuals (Grundman et al 2004). The main complaint in MCI patients is memory loss, and $84 \%$ of patients diagnosed with MCI progress to full AD as they age (Morris et al 2001). The study of MCI may thus provide ample information about the progression of $\mathrm{AD}$.

The neuropathology of AD has been extensively characterized. Brains from AD patients exhibit cortical atrophy and dilation of the ventricles (Tomlinson et al 1970) as well as the progressive appearance of amyloid deposits (plaques) and neurofibrillary tangles beginning in the isocortical area and spreading through the hippocampus and, finally, pervading almost all of the cortical regions (Braak and Braak 1991). The accumulation of these amyloid plaques and neurofibrillary tangles has been strongly correlated with neuron loss (Mann et al 1985) and brains of AD patients show a progressive synaptic loss as well as astrogliosis increasing with the duration of the disease (Ingelsson et al 2004). The core protein of the senile plaques in $\mathrm{AD}$ was identified as amyloid- $\beta(\mathrm{A} \beta)$, 
a 4 kilodalton protein of 40 or 42 amino acids (Masters et al $1985)$ that is the product of sequential proteolytic cleavage of the APP by $\beta$-and $\gamma$-secretase (Tanzi and Bertram 2005). The neurofibrillary tangles (NFTs) are composed of paired helical fragments (PHF) containing hyperphosphorylated forms of the microtubule-associated protein tau (GrundkeIqbal et al 1986a 1986b). Both $A \beta$ and tau will be discussed thoroughly later in this chapter. Amyloid- $\beta$ first accumulates into diffuse plaques, which are then thought to progress into fibrillar, neuritic plaques (Selkoe and Schenk 2003; Turner 2006). The diffuse plaques can be seen in non-AD patients, and have been hypothesized to be a pre-clinical lesion; neuritic plaques are more tightly correlated with full cases of AD. Neuritic plaques are surrounded by dystrophic neurites, some with neurofibrillary changes, as well as by microglia, astrocytes, and inflammation (McGeer et al 1987; Selkoe and Schenk 2003). NFTs form in the soma of the neuron, and, once the neuron has died, the bundles of paired helical fragments remain behind as a "ghost tangle," soon disposed of by astrocytes (Braak and Braak 1991). NFTs are also seen in a number of other neurodegenerative diseases, classified as tauopathies, such as the familial frontotemporal dementias with parkinsonism linked to chromosome 17 (FTDP-17) (Spillantini et al 1998). Only in cases where both amyloid plaques and NFTs are present in brain tissue at autopsy, then, is a diagnosis of $\mathrm{AD}$ certain. The brains of $\mathrm{AD}$ patients also show vascular changes, most prominently deposition of $A \beta$ in leptomeningeal and neocortical vessels, known as cerebral amyloid angiopathy or congophilic amyloid angiopathy (CAA) (Thal et al 2003). While AD patients exhibit a far more severe extent of CAA than controls, it is still somewhat poorly understood whether CAA plays an important role in the development of $\mathrm{AD}$, although it has been proposed that accumulation of $A \beta$ in blood vessels may impact the normal elimination of $A \beta$ by reducing the flow of blood out of the brain. This would then result in more accumulation of $\mathrm{A} \beta$ inside the brain, contributing to the formation of senile plaques (Nicoll et al 2004).

$A D$ results in neurotransmitter dysfunctions, most prominently in the cholinergic system. A reduction in choline acetyltransferase activity has been identified in postmortem AD brains (Davies and Maloney 1976; Perry et al 1977). This deficit has been correlated to the number of senile plaques present in the patient's brain as well as to their level of cognitive deficit (Perry et al 1978; Wilcock et al 1982). The neurons in a region of the forebrain known as the nucleus basalis of Meynert, the origin of most of the cholinergic innervation in the cortex, undergo a selective degeneration resulting in the loss of $>75 \%$ of the neuron population in AD brain (Whitehouse et al 1982). More recently, deficits in choline acetlytransferase activity have been identified in very early stages of $A D$, coinciding with the very beginning of $A \beta$ deposition (Beach et al 2000). Loss of neurons in other neurotransmitter systems, such as GABA, glutamate, serotonin, and others, has also been reported in AD (Perry et al 1977; Selkoe and Schenk 2003). The major protein found in the core of senile plaques in $\mathrm{AD}$, amyloid- $\beta$, is derived from proteolytic processing of the APP (Tanzi and Bertram $2005)$. The amyloid- $\beta$ protein was identified and sequenced from the brains of Alzheimer's and Down's syndrome (DS) patients, who also exhibit AD-like pathology as they age (Wisniewski et al 1985; Mann 1988). The $4 \mathrm{kDa}$ amyloid- $\beta$ protein was found in the amyloid accumulations in the brain blood vessels of AD and DS patients (Glenner and Wong 1984a, 1984b), and finally identified as the core protein in AD senile plaques (Masters et al 1985; Wong et al 1985). This protein was conserved in senile plaques found in several species of aging mammals (Selkoe et al 1987).

The normal physiological role of APP is still relatively poorly understood, but seems to be involved in development. Knockout of one copy of the C. elegans ortholog, APL-1, causes defects in pharyngeal pumping (Zambrano et al 2002), while knockout of both copies is lethal at the larval stage (Hornsten et al 2007). Deletion of the Drosophila ortholog of APP, APPL, causes defects in axonal transport (Gunawardena and Goldstein 2001). Mice defective in APP exhibit various neuroanatomical and behavioral deficits (Muller et al 1994; Zheng et al 1995), including hypersensitivity to seizures (Steinbach et al 1998), impaired spatial learning and deficits in long-term potentiation (LTP) (Dawson et al 1999; Seabrook et al 1999). These defects in the APP knockout mice can however be rescued by expression of the soluble fragment of APP sAPP $\alpha$ (Ring et al 2007).

The association of AD pathology with Downs syndrome allowed the localization of the genetic defect in several families with genetic early-onset AD to chromosome 21 (St George-Hyslop et al 1987), and the cloning and identification of APP (Goldgaber et al 1987; Tanzi et al 1987). APP was then further identified as a type I transmembrane protein ( $\mathrm{N}$-terminus on the laminar side, $\mathrm{C}$-terminus facing the cytoplasm) of 695 amino acids that resembled a cell surface receptor (Kang et al 1987; Hardy and Selkoe 2002). The 695 amino acid form of APP is expressed in neurons; there are two alternatively spliced isoforms of APP expressed in other cell populations but not neurons (Gralle and Ferreira 2007). These two forms, of 751 and 770 amino acids, contain 
a Kunitz-type protease inhibitor (KPI) domain not found in the 695 amino acid isoform (Kitaguchi et al 1988; Ponte et al 1988; Tanzi et al 1988). The 770 amino acid isoform of APP contains a stretch of 19 amino acids with no known homology following the KPI domain (Richards et al 1995). The first mutation to be found to cause early onset autosomal dominant familial AD (FAD) was in APP (Goate et al 1991), and many more mutations in APP have been found to segregate with FAD (Papassotiropoulos et al 2006). The association of Down's syndrome (DS) with AD pathology in aging patients (Wisniewski et al 1985; Mann 1988; Stanton et al 2004; Teipel and Hampel 2006) was the first clue to the origin of $A \beta$ (Glenner and Wong 1984) and the location of the gene for APP on chromosome 21 (St George-Hyslop et al 1987). Mutations causing autosomal dominant familial early onset AD (FAD) were first identified in the genes for APP (Goate et al 1991), PS1 (Sherrington et al 1995) and PS2 (Levy-Lahad et al 1995). By 2006, 20 FAD mutations in the APP gene, 12 FAD mutations in PS2, and more than 150 FAD mutations in PS1 had been identified (Mayeux 2006; Papassotiropoulos et al 2006). A gene duplication of APP (Rovelet-Lecrux et al 2006) and promoter mutations causing APP overexpression (Theuns et al 2006) have also been associated with familial AD. Mutations causing FAD most often cause an increase in $\mathrm{A} \beta$ production (Citron et al 1992; Cai et al 1993; Haass et al 1994), possibly accompanied by increases in the ratio of the more amyloidogenic A $\beta 42$ to A $\beta 40$ (Suzuki et al 1994; Walker et al 2005).

The only genetic marker that segregates significantly with sporadic AD is the ApoE allele $\varepsilon 4$. The $\varepsilon 4$ allele of ApoE was identified as a risk factor for sporadic AD (Poirier et al 1993; Saunders et al 1993). Possession of this allele is considered to be the highest risk factor for developing sporadic AD, and even modifies the onset of FAD (Papassotiropoulos et al 2006). Recently, a polymorphism in the GRB-associated protein 2 (GAB2) gene was found to amplify even further the risk of $\mathrm{AD}$ in ApoE $\varepsilon 4$ carriers (Reiman et al 2007). Polymorphisms in other genes or their promoters, such as those for some proinflammatory cytokines (Du et al 2000; McCusker et al 2001; Ma et al 2004), and proteins that bind to the low-density lipoprotein receptor family (Herz and Beffert 2000) have also been identified, but meta-analyses have not identified the overall importance of these mutations in sporadic AD.

\section{Inflammation in AD}

The association between neuroinflammation and neurodegenerative diseases, including $\mathrm{AD}$, has been investigated extensively (Akiyama et al 2000; Wyss-Coray and
Mucke 2002; McGeer and McGeer 2003; Mrak and Griffin 2005; Eikelenboom et al 2006; Griffin 2006; Hoozemans et al 2006). One of the earliest consequences of $A \beta$ deposition is neuroinflammation, and it has been associated with neurodegeneration and progression of pathology (Craft et al 2006).

There are many indicators of the upregulation of proinflammatory signaling in AD patients. The immune cells of AD patients have been shown to produce significantly more of the cytokines IL-1 $\beta$, TNF, IL- 6 and IL-10 when challenged with a pro-inflammatory stimulus, with the levels of cytokines elicited increasing with the severity of the disease (Lombardi et al 1999). TNF levels are also increased in patients with severe AD compared to mild AD patients (Paganelli et al 2002). Cyclooxygenase 2 (COX2), a pro-inflammatory protein that is one of the targets of NSAIDs, is elevated in AD brains (Lukiw and Bazan 2000); so is its homolog, COX-1 (Kitamura et al 1999). Serum levels of the acute phase protein $\alpha 1$-antichymotrypsin, which is upregulated by injury, trauma and infection, are also significantly higher in AD patients than healthy controls (Lieberman et al 1995).

There appears to be a feedback signaling loop between $A \beta$ and IL-1 $\beta$ (Griffin et al 1998): $A \beta$ can induce the production of IL-1 $\beta$ (Mrak et al 1995), and the presence of IL-1 $\beta$ greatly increases the secretion of cytokines IL- 6 and IL- 8 in response to $\mathrm{A} \beta$ by astrocytes; in the other direction, IL- $1 \alpha$ and IL-1 $\beta$ both upregulate the expression of APP, thus probably upregulating the production of $A \beta$ (Sheng et al 1996) The ratio of the pro-inflammatory cytokine IL-1 $\beta$ to the anti-inflammatory cytokine IL-10 is drastically elevated in the serum of $\mathrm{AD}$ patients, giving these patients a definite pro-inflammatory profile (Remarque et al 2001). Increases in levels of IL-1 $\beta$ have been correlated with decreases in LTP in the hippocampus, showing that the cytokine itself may impair memory (Lynch 1998). IL-1 $\beta$, however, may not be all bad in AD pathogenic processes; recently, IL-1 $\beta$ was shown to upregulate the $\alpha$-secretase TACE, thus increasing nonamyloidogenic cleavage of APP and decreasing A $\beta$ production (Tachida et al 2007).

Several polymorphisms in the promoter region of TNF have been associated with AD (McCusker et al 2001; Ma et al 2004); the importance of TNF in AD will be discussed later in this article. A polymorphism in the IL- $1 \alpha$ gene has also been associated with risk of AD (Du et al 2000). IL-6 (Hull et al 1996) and early components of the complement cascade (C1, C3, and C4), but not late component system proteins (Eikelenboom and Veerhuis 1996) have also been found in and around amyloid plaques, contributing to the overall neuroinflammatory environment. 
The transforming growth factor- $\beta$ (TGF- $\beta$ ) cytokines are also present in plaques in AD brain (van der Wal et al 1993). TGF- $\beta 1$ increases $A \beta$ accumulation in the cerebral blood vessels of mice transgenic for human APP and is upregulated in blood vessels of human patients with CAA (Wyss-Coray et al 1997). Co-addition of TGF- $\beta 1,2$ and 3 isoforms with $A \beta$ causes increased $A \beta$ accumulation in organotypic hippocampal slices, with the patterns of accumulation for each TGF- $\beta$ isoform slightly different (Harris-White et al 1998).

Not all of the inflammatory responses in AD brain are negative: the peroxisome proliferator-activated receptor- $\gamma(\operatorname{PPAR} \gamma)$, a nuclear receptor which is activated by metabolites of prostaglandins generated by the COX enzymes and by certain NSAIDs, is upregulated in concert with the COX enzymes in AD brain (Kitamura et al 1999). PPAR $\gamma$ activation exerts an antiinflammatory effect, and PPAR $\gamma$ agonists have been shown to inhibit the production of cytokines and pro-inflammatory mediators in response to $A \beta$ (Combs et al 2000).

Lastly, the pro-inflammatory effect of $A \beta$ deposition in brain has been recapitulated in aged mice transgenic for a familial AD mutation of APP, in which astrocytes and microglia expressing Il-1 $\beta$, IL-6 and TNF have been found surrounding amyloid plaques (Benzing et al 1999). It has also been found that the bacterial endotoxin LPS, a powerful inducer of inflammatory responses (Flick and Gifford, 1986), exacerbates the appearance and severity of $\mathrm{AD}$ pathology in the APP ${ }^{\mathrm{V} 717 \mathrm{~F}}$ transgenic mouse (Qiao et al 2001), the $\mathrm{APP}_{\text {swe }}$ transgenic mouse (Sheng et al 2003), and the triple-transgenic $(3 \times \mathrm{TgAD})$ mouse (Kitazawa et al 2005).

Microglia are the resident macrophages in the brain; they establish themselves and differentiate there during development (Perry and Gordon, 1988). Microglia have been found associated with amyloid plaques in $\mathrm{AD}$ brain (McGeer et al 1987). These cells are activated by and capable of removing A $\beta$ in vitro (Shaffer et al 1995; Ard et al 1996; Kopec and Carroll 1998). However, in the presence of inflammatory cytokines or certain extracellular matrix proteins, microglia cannot phagocytize $A \beta$ (Koenigsknecht-Talboo and Landreth 2005), which may explain how plaques are able to accumulate in vivo. IL- $1 \alpha$ positive (ie, pro-inflammatory) microglia are increased in number in the cortical layers affected by plaque pathology in AD patients (Sheng et al 1998).

As microglia are found in large numbers focally distributed around neuritic amyloid plaques, but not diffuse plaques, it has been postulated that microglia play a role in the conversion from diffuse to neuritic senile plaques, but not in the origin of diffuse plaques (Mackenzie et al 1995). The accumulation of microglia around amyloid plaques is seen not only in human $\mathrm{AD}$ patients, but also in mice transgenic for mutant APP (Frautschy et al 1998). They exhibit an enlarged, activated phenotype, and are positive for IL-1 $\beta$ and TNF in these animals (Benzing et al 1999). Similarly, in humans, microglia display an activated phenotype when they surround plaques, and can be recognized by the same activation markers one would employ to detect activated macrophages (McGeer and McGeer 2003), such as the Human Leukocyte Antigen-DR (HLA-DR) (McGeer et al 1987). Microglia not only produce cytokines and other pro-inflammatory mediators (Akiyama et al 2000; Eikelenboom et al 2002), they can also kill neurons that have been damaged by $\mathrm{A} \beta$ (Bate et al 2004). It is thus becoming widely accepted that microglia play a role in the pathology of AD.

Epidemiological studies suggest a link between chronic use of NSAIDs and reduced risk for AD. In a study of siblings who all eventually developed $A D$, regular use of NSAIDs delayed the onset of $\mathrm{AD}$ and reduced the risk of $\mathrm{AD}$ each year (Breitner et al 1995). Analysis of a subset of the Rotterdam study revealed that use of NSAIDs for more than 6 months, especially in those aged 85 and younger, significantly reduced the risk of AD (in 't Veld et al 1998). Participants in the Baltimore Longitudinal Aging Study also exhibited a reduced risk for AD with the use of NSAIDs, with those patients who had taken NSAIDs for more than 2 years showing the most reduction in AD risk (Stewart et al 1997).

Comparison of brains of aged nondemented patients who used NSAIDs chronically with nondemented patients who did not use NSAIDs revealed no changes in the appearance of senile plaques, but a 3-fold decrease in the number of activated microglia in the brains of NSAID users (Mackenzie and Munoz 1998), pointing at a microglial mode of action for the protection afforded by chronic NSAID use in studies of $A D$ patients. In a transgenic mouse model of $\mathrm{AD}$, chronic ibuprofen administration to aged mice reduced the number and area of amyloid plaques, as well as the numbers of activated microglia (Lim et al 2000), and administration of R-flurbiprofen rescued deficits in hippocampal and medial temporal lobe-dependent memory and learning (Kukar et al 2007). However, thus far, clinical trials using systemic administration have yielded mixed or inconclusive results (Launer 2003; van Gool et al 2003; McGeer and McGeer 2007), reflecting the need to identify and target the key inflammatory mediators that promote amyloid-associated neuropathology.

\section{Tumor necrosis factor signaling}

First identified as a serum factor produced in mice in response to endotoxin and capable of killing tumor cells 
(Carswell et al 1975), TNF (previously referred to in the literature as TNF $\alpha$ ) begins as a type II transmembrane protein which exists as a homotrimer (Kriegler et al 1988; Tang et al 1996). The soluble cytokine TNF (solTNF) is released from the membrane by cleavage of this pro- or transmembrane TNF (tmTNF) by ADAM17, also known as TNF- $\alpha$ cleavage enzyme (TACE) (Black et al 1997). Cloned in 1985, solTNF is a $17 \mathrm{kDa}$ protein (Shirai et al 1985) that functions as a $51 \mathrm{kDa}$ homotrimer (Wajant et al 2003).

TNF is vital in immune system development and continued immunity. TNF knockout mice are deficient in splenic $\mathrm{B}$ cell follicles and follicular dendritic cell networks and are unable to respond to endotoxin and Candida albicans and Mycobacterium tuberculosis infections (Flynn et al 1995; Pasparakis et al 1996; Marino et al 1997). TNF has been used as an anti-cancer therapy, but its effectiveness is disputed (Bertazza and Mocellin 2008). TNF is the first member of a superfamily of related proteins and receptors, with 20 ligands and 29 receptors (reviewed in Bertazza and Mocellin 2008).

Cells can express two different TNF receptors, TNFR1 and TNFR2. Most cells express TNFR1, but the expression of TNFR2 is more tightly regulated.TNFR2 is mainly, but not only, expressed in immune cells. Both receptors are very similar in their extracellular domains, but TNFR2 does not contain a death domain, which is an important protein-protein interaction domain. Instead, TNFR2 has a cytoplasmic domain that is able to bind TNF-receptor associated factors (TRAFs) (Varfolomeev and Ashkenazi 2004). Activation of the TNF receptor 1 (TNFR1) by binding of TNF can lead to a multitude of cellular responses, such as inflammation, proliferation, apoptosis, tumor necrosis, or cell differentiation (Liu et al 1996). TNFR1-deficient mice exhibit some of the same phenotypes as TNF knockout mice, including the poor response to infection (Vieira et al 1996; Wajant et al 2003). TNF induces the activation of the transcription factor NF- $\kappa$ B very rapidly and without the need for maximal receptor binding (Hohmann et al 1990). The signal from the TNFR1 complex to NF- $\mathrm{BB}$ is transduced through the adaptor protein TRAF2 (Bertazza and Mocellin 2008) to the death-domain kinase receptor-interacting protein 1 (RIP1), which has been found to be essential to TNF-induced NF- $\kappa B$ activation (Kelliher et al 1998). NF- $\kappa B$ activation leads to the transcription of many inflammatory cytokines, but also to the production of anti-apoptotic factors (Wajant et al 2003) and, thus, to cell survival. TNF also induces the activation of the apoptosis signaling kinase 1 (ASK1) through the adaptor protein TRAF2; ASK1 activity is required for the execution of TNF-induced apoptosis (Hoeflich et al 1999). The p38 Mitogen-Activated Protein Kinase (p38-MAPK) is activated by TNF signaling through TNFR1, with the signals transmitted by the death-domain kinase RIP1 (Lee et al 2003) and ASK1 (Hoeflich et al 1999). The c-Jun N-terminal kinase (JNK) can be activated by TNF signaling, through both TNFR1 (Liu et al 1996) and TNFR2 (Reinhard et al 1997), via TRAF2 and ASK1 (Hoeflich et al 1999). These stress activated protein kinases, p38MAPK and JNK, are transiently activated, though their activation is extended during apoptosis (Wajant et al 2003) by the activity of ASK1 (Tobiume et al 2001). TNF signaling through TNFR1 can also weakly activate other MAPKs, the extracellular signal regulated kinases (ERK) (Vietor et al 1993). Neither ERKs nor p38MAPK are activated by signaling through TNFR2 (Jupp et al 2001).

TNF can also mediate apoptosis, mostly through TNFR1, counteracting the survival signals it induces. Usually, TNFinduced killing can only happen when de novo transcription or translation are inhibited (which will prevent the synthesis of proteins regulated by $\mathrm{NF}-\kappa \mathrm{B}$ ) ( $\mathrm{Li}$ and $\mathrm{Beg} 2000)$. The TNF-induced apoptotic cascade is mediated by the activation of caspase- 8 . NF- $\mathrm{KB}$ activation leads to inhibition of caspase- 8 by c-FLIP, and thus blocks the execution of apoptosis. If NF- $\kappa \mathrm{B}$ fails to be properly activated, caspase- 8 is recruited to the TNFR1 receptor complex and become active (Micheau and Tschopp 2003). Caspase-8 cleaves RIP1 kinase at aspartate-324 (D324) (Lin et al 1999), and the C-terminal fragment thus released (containing the intermediate domain and death domain, but not the kinase domain) suppresses NF- $\kappa B$ activation and causes apoptosis (Kim et al 2000). When caspases are inhibited, TNF can also induce necrotic cell death (Li and Beg 2000). TNFR1 signaling induces the production of reactive oxygen species (ROS), which can induce cell death (Hennet et al 1993; Binder et al 1999; Moreno-Manzano et al 2000). However, the signaling by ROS can have a protective effect, as it induces the activa-

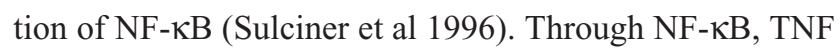
signaling activates the transcription of manganous superoxide dismutase (MnSOD), which scavenges ROS (Wong and Goeddel 1988). TNF signaling also activates the acidic sphingomyelinase (aSMase) and causes the production of ceramide, which can cause apoptosis (Obeid et al 1993) and has been implicated in TNF-induced necrotic cell death (Wajant et al 2003).

TNFR2 can interfere with apoptotic signaling by TNFR1 by activating the JNK pathway or the NF- $\mathrm{KB}$ pathway (Bertazza and Mocellin 2008). Alternatively, it can facilitate 
apoptosis by causing the degradation of the adaptor protein TRAF2 (Li et al 2002), thus preventing the activation of NF- $\kappa B$. Signaling through TNFR2 can only induce apoptosis when accompanied by signaling through TNFR1 (Wajant et al 2003). SolTNF signals primarily through TNFR1 (Grell et al 1998) and tmTNF (transmembrane TNF) signals primarily through TNFR2 (Grell et al 1995).

The involvement of TNF may be highly relevant in the context of the brain and specifically the hippocampus, considering that TNF signaling through TNFR2 is protective against glutamate excitotoxicity (Marchetti et al 2004), reduces seizures in response to kainic acid (Balosso et al 2005), and most likely promotes the survival of hippocampal neuroblasts after ischemic injury (Heldmann et al 2005). Systemic administration of drugs that inhibit both transmembrane and soluble TNF, such as etanercept, an Fc-fused recombinant TNFR2 (Murray and Dahl 1997), or infliximab, an antibody against TNF (Elliott et al 1994), have been associated with serious side effects including an increased susceptibility to infection and demyelinating disease (Scheinfeld 2004). These effects may be related to the ability of these biologics to inhibit tmTNF signaling, which plays an important role in resolving inflammation and maintaining immunity to certain pathogens (Alexopoulou et al 2006).

\section{TNF in Alzheimer's disease}

TNF signaling has been strongly implicated in AD pathology and overwhelming evidence now suggests that TNFdriven processes may contribute to cognitive dysfunction and accelerated progression of AD. Elevated serum levels of pro-inflammatory cytokines (Paganelli et al 2002), in particular TNF (Fillit et al 1991; Collins et al 2000; Alvarez et al 2007; Tan et al 2007), have been detected in patients with severe AD.

Overproduction of inflammatory mediators in the brain occurs when microglia, which are often found in close physical association with amyloid plaques in $\mathrm{AD}$ brains (McGeer et al 1987), become chronically activated. It has been proposed that elevated levels of pro-inflammatory cytokines, including TNF, may inhibit phagocytosis of $A \beta$ in $\mathrm{AD}$ brains thereby hindering efficient plaque removal by resident microglia (Koenigsknecht-Talboo and Landreth 2005). In support of this idea, the bacterial endotoxin LPS, a potent trigger of inflammation that elicits production of TNF and many other cytokines (Flick and Gifford 1986), can accelerate the appearance and severity of AD pathology in several animal models of AD (Qiao et al 2001; Sheng et al $2003)$, including the triple-transgenic $(3 \times$ TgAD $)$ mouse
(Kitazawa et al 2005), in which up-regulation of TNF mRNA precedes the appearance of amyloid pathology (Janelsins et al 2005) and correlates with cognitive deficits (Billings et al 2005).

In cell culture, TNF increases apoptosis of neurons treated with $\mathrm{A} \beta$ (Blasko et al 1997) and has been shown to affect $\mathrm{A} \beta$ production (Blasko et al 1999, 2000) through upregulation of both $\beta$-secretase expression (Yamamoto et al 2007) and $\gamma$-secretase activity (Liao et al 2004) as well as expression of APP itself (Lahiri et al 2003). Consistent with the role of TNF in regulation of APP processing, genetic deletion of the TNF receptor gene Tnfrsfla in the APP 23 transgenic mouse model reduced both the number of amyloid plaques and the cognitive deficits in these mice (He et al 2007). In humans, the TNF gene is considered to be a susceptibility locus for $\mathrm{AD}$, because polymorphisms in the TNF promoter have been associated with incidence of AD (McCusker et al 2001; Ma et al 2004); however, meta-analyses of multiple studies will be needed to assess the significance of this association.

Lastly, a recent report from a clinical pilot study suggests that long-term perispinal administration of the anti-TNF drug etanercept can improve cognitive performance in AD patients (Tobinick et al 2006) through an as yet unknown mechanism. In addition, a case study was published recently in which a patient with $\mathrm{AD}$ demonstrated cognitive improvement within hours of perispinal Etanercept administration (Tobinick and Gross 2008). Given that TNF appears to function as a gliotransmitter and has been demonstrated to have an important role in synaptic scaling (Beattie et al 2002; Stellwagen and Malenka 2006), any immediate effects of TNF inhibitors are likely to be related to these TNF activities.

\section{Immunization and anti-inflammatory therapies for $A D$}

The drugs currently in use for treatment of AD are the cholinesterase inhibitors donepezil, galantamine and rivastigmine (Birks 2006; Caselli et al 2006; Lleo et al 2006; Farlow and Cummings 2007). These drugs provide a small but significant improvement in cognitive function in AD patients by inhibiting the degradation of the neurotransmitter acetylcholine, allowing more of it to be present for synaptic transmission (Birks 2006; Caselli et al 2006). These drugs are often paired with memantine, an antagonist of the glutamatergic N-methyl-D-aspartate (NMDA) receptor; this drug protects neurons against glutamate excitotoxicity, and also provides a modest improvement in AD symptoms (Lleo et al 2006).

An interesting approach to treating amyloid pathology in $\mathrm{AD}$ has been the active or passive immunization against $\mathrm{A} \beta$. 
Immunizing PDAPP mice with $A \beta 42$ prevented or reduced the progression of $\mathrm{AD}$ pathology in these mice, depending on whether the immunization took place before or after the development of plaque pathology (Schenk et al 1999). Vaccination with $A \beta$ peptides also ameliorated cognitive deficits in mice transgenic for an FAD mutation in APP and an FAD mutation in PS1 (Morgan et al 2000). As an alternative delivery route, intranasal administration of $\mathrm{A} \beta$ peptides reduced amyloid deposition in AD mouse models (Lemere et al 2001, 2002). $A \beta$ vaccinations were also found successful in reducing $A \beta$ levels in two non-human primates, the rhesus monkey (Gandy et al 2004) and the Caribbean vervet (Lemere et al 2004).

A clinical trial of $A \beta 42$ vaccinations was undertaken by Elan Pharmaceuticals in AD patients, and the immunizations resulted in significant clearance of $A \beta$ and plaque removal in some of the patients (Nicoll et al 2003, 2006), as well as a slowing of the cognitive decline in patients who produced antibodies against the peptide (Hock et al 2003). Unfortunately, the immunization also resulted in dangerous T-lymphocyte meningoencephalitis in some patients, causing the arrest of these trials (Orgogozo et al 2003; Nicoll et al 2006). Passive immunizations with antibodies against $A \beta$ reduced plaque burden and AD pathology in PDAPP mice (Bard et al 2000), and administration of antibodies specifically directed against oligomers of $\mathrm{A} \beta$ improved learning and memory in Tg2576 mice (Lee et al 2006). This may be a safer approach with which to immunize AD patients (Lee et al 2006). There is also some evidence that using shorter $A \beta$ peptides is safer than using full-length $A \beta 40$ or 42 as the immunogen (Lemere et al 2007).

The reduction in risk of $\mathrm{AD}$ with chronic NSAID use is discussed above. The original interpretation of these data was that the classical action of NSAIDs inhibiting cyclooxygenase (COX) activities was responsible for the lowered risk of $\mathrm{AD}$; however, there is evidence that the action of NSAIDs in reducing the risk of $\mathrm{AD}$ may be through inhibition of other pathways (Lleo et al 2007). Some NSAIDs, including indomethacin and ibuprofen, are also PPAR $\gamma$ agonists, inhibiting the production of inflammatory molecules through that pathway (Lehmann et al 1997). Activation of PPAR $\gamma$ by NSAIDs also represses the expression of the $\beta$-secretase BACE (M. Sastre et al 2006). The protection by NSAIDs may also be due to their ability to inhibit the Rho GTPases, which can modulate $A \beta$ secretion, but not specifically $A \beta 42$ (Lleo et al 2007). Certain NSAIDs, in particular those related to ibuprofen, can selectively reduce the production of $A \beta 42$ (Weggen et al 2001) through modulation of $\gamma$-secretase activity (Eriksen et al 2003; Lleo et al 2004).
Unfortunately, though epidemiological studies indicate a protective benefit of NSAIDs in AD, clinical trials remain inconclusive (Lleo et al 2006).

\section{Conclusions and future directions}

There are many indicators of the upregulation of pro-inflammatory signaling in AD patients and overwhelming evidence now suggests that TNF-driven processes may contribute to cognitive dysfunction and accelerated progression of the disease. Although the TNF gene is considered to be a susceptibility locus for AD and polymorphisms in the TNF promoter have been associated with incidence of AD, meta-analyses of multiple studies will be needed to assess the significance of this association. Importantly, further validation of TNF as a therapeutic target must be undertaken in order to justify widespread clinical use of anti-TNF drugs in patients with AD. Pre-clinical findings with chronic NSAIDs strongly implicate inflammatory processes in progression of $\mathrm{AD}$ and will now need to be extended and replicated in well-designed clinical trials. Lastly, timely application of $A \beta$ immunization strategies hold great promise and will harness the power of the immune system to prevent or slow progression of AD. For this reason, other neuroimmune modulatory compounds merit exploration in pre-clinical studies and may turn out to be important components of the arsenal to combat this devastating disease.

\section{Disclosure}

The author(s) declare that they have no competing interests. The manuscript was written by FEM as part of her doctoral thesis. MGT provided historical perspectives and editorial assistance.

\section{References}

Akiyama H, Barger S, Barnum S, et al. 2000. Inflammation and Alzheimer's disease. Neurobiol Aging, 21:383-421.

Alvarez A, Cacabelos R, Sanpedro C, et al. 2007. Serum TNF-alpha levels are increased and correlate negatively with free IGF-I in Alzheimer disease. Neurobiol Aging, 28:533-6.

Alzheimer A. 1907. [Über eine eigenartige Erkrankung der Hirnrinde. Allgemeine Zeitschrift fur Psychiatrie under Psychisch-Gerichtliche Medizin]. 64:146-8.

Alzheimer A, Stelzmann RA, Schnitzlein HN, et al. 1995. An English translation of Alzheimer's 1907 paper, "Uber eine eigenartige Erkankung der Hirnrinde". Clin Anat, 8:429-31.

Balosso S, Ravizza T, Perego C, et al. 2005. Tumor necrosis factor-alpha inhibits seizures in mice via p75 receptors. Ann Neurol, 57:804-12.

Bard F, Cannon C, Barbour R, et al. 2000. Peripherally administered antibodies against amyloid beta-peptide enter the central nervous system and reduce pathology in a mouse model of Alzheimer disease. Nat Med, 6:916-9.

Bate C, Veerhuis R, Eikelenboom P, et al. 2004. Microglia kill amyloid-beta1-42 damaged neurons by a CD14-dependent process. Neuroreport, 15:1427-30. 
Beach TG, Kuo YM, Spiegel K, et al. 2000. The cholinergic deficit coincides with Abeta deposition at the earliest histopathologic stages of Alzheimer disease. J Neuropathol Exp Neurol, 59:308-13.

Beattie EC, Stellwagen D, Morishita W, et al. 2002. Control of synaptic strength by glial TNFalpha. Science, 295:2282-5.

Benzing WC, Wujek JR, Ward EK, et al. 1999. Evidence for glial-mediated inflammation in aged APP(SW) transgenic mice. Neurobiol Aging, 20:581-9.

Bertazza L, Mocellin S. 2008. Tumor necrosis factor (TNF) biology and cell death. Front Biosci, 13:2736-43.

Billings LM, Oddo S, Green KN, et al. 2005. Intraneuronal Abeta causes the onset of early Alzheimer's disease-related cognitive deficits in transgenic mice. Neuron, 45:675-88.

Birks J. 2006. Cholinesterase inhibitors for Alzheimer's disease. Cochrane Database Syst Rev, 1:CD005593.

Blasko I, Schmitt TL, Steiner E, et al. 1997. Tumor necrosis factor alpha augments amyloid beta protein (25-35) induced apoptosis in human cells. Neurosci Lett, 238:17-20.

Braak H, Braak E. 1991. Neuropathological stageing of Alzheimer-related changes. Acta Neuropathol, 82:239-59.

Breitner JC, Welsh KA, Helms MJ, et al. 1995. Delayed onset of Alzheimer's disease with nonsteroidal anti-inflammatory and histamine $\mathrm{H} 2$ blocking drugs. Neurobiol Aging, 16:523-30.

Cai XD, Golde TE, Younkin SG. 1993. Release of excess amyloid beta protein from a mutant amyloid beta protein precursor. Science, 259:514-16.

Carswell EA, Old LJ, Kassel RL, et al. 1975. An endotoxin-induced serum factor that causes necrosis of tumors. Proc Natl Acad Sci U S A, 72:3666-70

Caselli RJ, Beach TG, Yaari R, et al. 2006. Alzheimer's disease a century later. J Clin Psychiatry, 67:1784-800.

Citron M, Oltersdorf T, Haass C, et al. 1992. Mutation of the beta-amyloid precursor protein in familial Alzheimer's disease increases beta-protein production. Nature, 360:672-4.

Collins JS, Perry RT, Watson B Jr., et al. 2000. Association of a haplotype for tumor necrosis factor in siblings with late-onset Alzheimer disease: the NIMH Alzheimer Disease Genetics Initiative. Am J Med Genet, 96:823-30.

Eikelenboom P, Veerhuis R. 1996. The role of complement and activated microglia in the pathogenesis of Alzheimer's disease. Neurobiol Aging, 17:673-80.

Evans DA. 1990. Estimated prevalence of Alzheimer's disease in the United States. Milbank Q, 68:267-89.

Farlow MR, Cummings JL. 2007. Effective pharmacologic management of Alzheimer's disease. Am J Med, 120:388-97.

Fillit H, Ding WH, Buee L, et al. 1991. Elevated circulating tumor necrosis factor levels in Alzheimer's disease. Neurosci Lett, 129:318-20.

Flick DA, Gifford GE. 1986. Production of tumor necrosis factor in unprimed mice: mechanism of endotoxin-mediated tumor necrosis Immunobiology, 171:320-8.

Frautschy SA, Yang F, Irrizarry M, et al. 1998. Microglial response to amyloid plaques in APPsw transgenic mice. Am J Pathol, 152:307-17.

Gandy S, DeMattos RB, Lemere CA, et al. 2004. Alzheimer's Abeta vaccination of rhesus monkeys (Macaca mulatta). Mech Ageing Dev, 125:149-51.

Glenner GG, Wong CW. 1984. Alzheimer's disease and Down's syndrome: sharing of a unique cerebrovascular amyloid fibril protein. Biochem Biophys Res Commun, 122:1131-5.

Goate A, Chartier-Harlin MC, Mullan M, et al. 1991. Segregation of a missense mutation in the amyloid precursor protein gene with familial Alzheimer's disease. Nature, 349:704-6.

Graeber MB, Mehraein P. 1999. Reanalysis of the first case of Alzheimer's disease. Eur Arch Psychiatry Clin Neurosci, 249(Suppl 3):10-3.

Gralle M, Ferreira ST. 2007. Structure and functions of the human amyloid precursor protein: the whole is more than the sum of its parts. Prog Neurobiol, 82:11-32.

Grell M, Wajant H, Zimmermann G, et al. 1998. The type 1 receptor (CD120a) is the high-affinity receptor for soluble tumor necrosis factor. Proc Natl Acad Sci U S A, 95:570-5.
Griffin WS, Sheng JG, Royston MC, et al. 1998. Glial-neuronal interactions in Alzheimer's disease: the potential role of a 'cytokine cycle' in disease progression. Brain Pathol, 8:65-72.

Gunawardena S, Goldstein LS. 2001. Disruption of axonal transport and neuronal viability by amyloid precursor protein mutations in Drosophila. Neuron, 32:389-401.

Harris-White ME, Chu T, Balverde Z, Sigel JJ, et al. 1998. Effects of transforming growth factor-beta (isoforms 1-3) on amyloid-beta deposition, inflammation, and cell targeting in organotypic hippocampal slice cultures. J Neurosci, 18:10366-74.

He P, Zhong Z, Lindholm K, et al. 2007. Deletion of tumor necrosis factor death receptor inhibits amyloid \{beta\} generation and prevents learning and memory deficits in Alzheimer's mice. $J$ Cell Biol, 178:829-41.

Hebert LE, Scherr PA, Bienias JL, et al. 2003. Alzheimer disease in the US population: prevalence estimates using the 2000 census. Arch Neurol, 60:1119-22.

Heldmann U, Thored P, Claasen JH, et al. 2005. TNF-alpha antibody infusion impairs survival of stroke-generated neuroblasts in adult rat brain. Exp Neurol, 196:204-8.

Herz J, Beffert U. 2000. Apolipoprotein E receptors: linking brain development and Alzheimer's disease. Nat Rev Neurosci, 1:51-8.

Hock C, Konietzko U, Streffer JR, et al. 2003. Antibodies against betaamyloid slow cognitive decline in Alzheimer's disease. Neuron, 38:547-54.

Hoeflich KP, Yeh WC, Yao Z, et al. 1999. Mediation of TNF receptor-associated factor effector functions by apoptosis signal-regulating kinase-1 (ASK1). Oncogene, 18:5814-20.

Hohmann HP, Remy R, Poschl B, et al. 1990. Tumor necrosis factors-alpha and -beta bind to the same two types of tumor necrosis factor receptors and maximally activate the transcription factor NF-kappa B at low receptor occupancy and within minutes after receptor binding. $J$ Biol Chem, 265:15183-8.

Hornsten A, Lieberthal J, Fadia S, et al. 2007. APL-1, a Caenorhabditis elegans protein related to the human beta-amyloid precursor protein, is essential for viability. Proc Natl Acad Sci U S A, 104:1971-6.

Hull M, Fiebich BL, Lieb K, et al. 1996. Interleukin-6-associated inflammatory processes in Alzheimer's disease: new therapeutic options. Neurobiol Aging, 17:795-800.

In 't Veld BA, Launer LJ, Hoes AW, et al. 1998. NSAIDs and incident Alzheimer's disease. The Rotterdam Study. Neurobiol Aging, 19:607-11.

Janelsins MC, Mastrangelo MA, Oddo S, et al. 2005. Early correlation of microglial activation with enhanced tumor necrosis factor-alpha and monocyte chemoattractant protein-1 expression specifically within the entorhinal cortex of triple transgenic Alzheimer's disease mice. J Neuroinflammation, 2:23.

Kitazawa M, Oddo S, Yamasaki TR, et al. 2005. Lipopolysaccharide-induced inflammation exacerbates tau pathology by a cyclin-dependent kinase 5 -mediated pathway in a transgenic model of Alzheimer's disease. J Neurosci, 25:8843-53.

Koenigsknecht-Talboo J, Landreth GE. 2005. Microglial phagocytosis induced by fibrillar beta-amyloid and IgGs are differentially regulated by proinflammatory cytokines. $J$ Neurosci, 25:8240-9.

Kukull WA, Higdon R, Bowen JD, et al. 2002. Dementia and Alzheimer disease incidence: a prospective cohort study. Arch Neurol, 59:1737-46.

Lee EB, Leng LZ, Zhang B, et al. 2006. Targeting amyloid-beta peptide (Abeta) oligomers by passive immunization with a conformationselective monoclonal antibody improves learning and memory in Abeta precursor protein (APP) transgenic mice. J Biol Chem, 281:4292-9.

Lehmann JM, Lenhard JM, Oliver BB, et al. 1997. Peroxisome proliferatoractivated receptors alpha and gamma are activated by indomethacin and other non-steroidal anti-inflammatory drugs. J Biol Chem, 272:3406-10.

Lemere CA, Maron R, Selkoe DJ, et al. 2001. Nasal vaccination with betaamyloid peptide for the treatment of Alzheimer's disease. DNA Cell Biol, 20:705-11.

Lemere CA, Spooner ET, Leverone JF, et al. 2002. Intranasal immunotherapy for the treatment of Alzheimer's disease: Escherichia coli LT and LT(R192G) as mucosal adjuvants. Neurobiol Aging, 23:991-1000. 
Lemere CA, Maier M, Peng Y, et al. 2007. Novel Abeta immunogens: is shorter better? Curr Alzheimer Res, 4:427-36.

Lemere CA, Beierschmitt A, Iglesias M, et al. 2004. Alzheimer's disease abeta vaccine reduces central nervous system abeta levels in a nonhuman primate, the Caribbean vervet. Am J Pathol, 165:283-97.

Lemere CA, Lopera F, Kosik KS, et al. 1996. The E280A presenilin 1 Alzheimer mutation produces increased A beta 42 deposition and severe cerebellar pathology. Nat Med, 2:1146-50.

Li M, Beg AA. 2000. Induction of necrotic-like cell death by tumor necrosis factor alpha and caspase inhibitors: novel mechanism for killing virusinfected cells. $J$ Virol, 74:7470-7.

Li X, Yang Y, Ashwell JD. 2002. TNF-RII and c-IAP1 mediate ubiquitination and degradation of TRAF2. Nature, 416:345-7.

Lieberman J, Schleissner L, Tachiki KH, et al. 1995. Serum alpha 1-antichymotrypsin level as a marker for Alzheimer-type dementia. Neurobiol Aging, 16:747-53.

Lleo A, Greenberg SM, Growdon JH. 2006. Current pharmacotherapy for Alzheimer's disease. Annu Rev Med, 57:513-33.

Lleo A, Galea E, Sastre M. 2007. Molecular targets of non-steroidal antiinflammatory drugs in neurodegenerative diseases. Cell Mol Life Sci, 64:1403-18

Lopera F, Ardilla A, Martinez A, et al. 1997. Clinical features of earlyonset Alzheimer disease in a large kindred with an E280A presenilin-1 mutation. JAMA, 277:793-9.

Lukiw WJ, Bazan NG. 2000. Neuroinflammatory signaling upregulation in Alzheimer's disease. Neurochem Res, 25:1173-84.

Ma SL, Tang NL, Lam LC, et al. 2004. Association between tumor necrosis factor-alpha promoter polymorphism and Alzheimer's disease. Neurology, 62:307-9.

Mackenzie IR, Munoz DG. 1998. Nonsteroidal anti-inflammatory drug use and Alzheimer-type pathology in aging. Neurology, 50:986-90.

Mackenzie IR, Hao C, Munoz DG. 1995. Role of microglia in senile plaque formation. Neurobiol Aging, 16:797-804.

Mann DM, Yates PO, Marcyniuk B. 1985. Correlation between senile plaque and neurofibrillary tangle counts in cerebral cortex and neuronal counts in cortex and subcortical structures in Alzheimer's disease. Neurosci Lett, 56:51-5.

Masters CL, Simms G, Weinman NA, et al. 1985. Amyloid plaque core protein in Alzheimer disease and Down syndrome. Proc Natl Acad Sci U S A, 82:4245-9.

McGeer EG, McGeer PL. 2003. Inflammatory processes in Alzheimer's disease. Prog Neuropsychopharmacol Biol Psychiatry, 27:741-9.

McGeer PL, Itagaki S, Tago H, et al. 1987. Reactive microglia in patients with senile dementia of the Alzheimer type are positive for the histocompatibility glycoprotein HLA-DR. Neurosci Lett, 79:195-200.

Morgan D, Diamond DM, Gottschall PE, et al. 2000. A beta peptide vaccination prevents memory loss in an animal model of Alzheimer's disease. Nature, 408:982-5.

Morris JC, Storandt M, Miller JP, et al. 2001. Mild cognitive impairment represents early-stage Alzheimer disease. Arch Neurol, 58:397-405.

Morris RG, Salmon DP. 2007. The centennial of Alzheimer's disease and the publication of "Uber eine eigenartige Erkankung der Hirnrinde" by Alois Alzheimer. Cortex, 43:821-5.

Mrak RE, Sheng JG, Griffin WS. 1995. Glial cytokines in Alzheimer's disease: review and pathogenic implications. Hum Pathol, 26:816-23.

Murray KM, Dahl SL. 1997. Recombinant human tumor necrosis factor receptor (p75) Fc fusion protein (TNFR:Fc) in rheumatoid arthritis. Ann Pharmacother, 31:1335-38.

Nee LE, Polinsky RJ, Eldridge R, et al. 1983. A family with histologically confirmed Alzheimer's disease. Arch Neurol, 40:203-8.

Nicoll JA, Yamada M, Frackowiak J, et al. 2004. Cerebral amyloid angiopathy plays a direct role in the pathogenesis of Alzheimer's disease. Pro-CAA position statement. Neurobiol Aging, 25:589-97; discussion 603-4.

Nicoll JA, Wilkinson D, Holmes C, et al. 2003. Neuropathology of human Alzheimer disease after immunization with amyloid-beta peptide: a case report. Nat Med, 9:448-52.
Nicoll JA, Barton E, Boche D, et al. 2006. Abeta species removal after abeta42 immunization. J Neuropathol Exp Neurol, 65:1040-8.

Obeid LM, Linardic CM, Karolak LA, et al. 1993. Programmed cell death induced by ceramide. Science, 259:1769-71.

Orgogozo JM, Gilman S, Dartigues JF, et al. 2003. Subacute meningoencephalitis in a subset of patients with $\mathrm{AD}$ after Abeta 42 immunization. Neurology, 61:46-54.

Paganelli R, Di Iorio A, Patricelli L, et al. 2002. Proinflammatory cytokines in sera of elderly patients with dementia: levels in vascular injury are higher than those of mild-moderate Alzheimer's disease patients. Exp Gerontol, 37:257-63.

Papassotiropoulos A, Fountoulakis M, Dunckley T, et al. 2006. Genetics, transcriptomics, and proteomics of Alzheimer's disease. $J$ Clin Psychiatry, 67:652-70.

Perry VH, Gordon S. 1988. Macrophages and microglia in the nervous system. Trends Neurosci, 11:273-77.

Pinquart M, Sorensen S. 2003. Differences between caregivers and noncaregivers in psychological health and physical health: a meta-analysis. Psychol Aging, 18:250-67.

Qiao X, Cummins DJ, Paul SM. 2001. Neuroinflammation-induced acceleration of amyloid deposition in the APPV717F transgenic mouse. Eur J Neurosci, 14:474-82.

Rathmann KL, Conner CS. 2007. Alzheimer's disease: clinical features, pathogenesis, and treatment. 1984. Ann Pharmacother, 41:1499-504.

Remarque EJ, Bollen EL, Weverling-Rijnsburger AW, et al. 2001. Patients with Alzheimer's disease display a pro-inflammatory phenotype. Exp Gerontol, 36:171-6.

Richards SJ, Hodgman C, Sharpe M. 1995. Reported sequence homology between Alzheimer amyloid770 and the MRC OX-2 antigen does not predict function. Brain Res Bull, 38:305-6.

Rovelet-Lecrux A, Hannequin D, Raux G, et al. 2006. APP locus duplication causes autosomal dominant early-onset Alzheimer disease with cerebral amyloid angiopathy. Nat Genet, 38:24-6.

Scheinfeld N. 2004. A comprehensive review and evaluation of the side effects of the tumor necrosis factor alpha blockers etanercept, infliximab and adalimumab. J Dermatolog Treat, 15:280-94.

Schenk D, Barbour R, Dunn W, et al. 1999. Immunization with amyloidbeta attenuates Alzheimer-disease-like pathology in the PDAPP mouse. Nature, 400:173-7.

Selkoe DJ, Bell DS, Podlisny MB, et al. 1987. Conservation of brain amyloid proteins in aged mammals and humans with Alzheimer's disease. Science, 235:873-7.

Sheng JG, Griffin WS, Royston MC, et al. 1998. Distribution of interleukin1-immunoreactive microglia in cerebral cortical layers: implications for neuritic plaque formation in Alzheimer's disease. Neuropathol Appl Neurobiol, 24:278-83.

Sheng JG, Bora SH, Xu G, et al. 2003. Lipopolysaccharide-induced-neuroinflammation increases intracellular accumulation of amyloid precursor protein and amyloid beta peptide in APPswe transgenic mice. Neurobiol Dis, 14:133-45.

Shirai T, Yamaguchi H, Ito H, et al. 1985. Cloning and expression in Escherichia coli of the gene for human tumour necrosis factor. Nature, 313:803-6.

Spillantini MG, Murrell JR, Goedert M, et al. 1998. Mutation in the tau gene in familial multiple system tauopathy with presenile dementia. Proc Natl Acad Sci U S A, 95:7737-41.

St George-Hyslop PH, Tanzi RE, Polinsky RJ, et al. 1987. The genetic defect causing familial Alzheimer's disease maps on chromosome 21. Science, 235:885-90.

Stellwagen D, Malenka RC. 2006. Synaptic scaling mediated by glial TNFalpha. Nature, 440:1054-9.

Stewart WF, Kawas C, Corrada M, et al. 1997. Risk of Alzheimer's disease and duration of NSAID use. Neurology, 48:626-32.

Sulciner DJ, Irani K, Yu ZX, et al. 1996. rac1 regulates a cytokine-stimulated, redox-dependent pathway necessary for NF-kappaB activation. $\mathrm{Mol}$ Cell Biol, 16:7115-21. 
Tachida Y, Nakagawa K, Saito T, et al. 2007. Interleukin-1beta up-regulates TACE to enhance alpha-cleavage of APP in neurons: resulting decrease in Abeta production. $J$ Neurochem,

Tan ZS, Beiser AS, Vasan RS, et al. 2007. Inflammatory markers and the risk of Alzheimer disease: the Framingham Study. Neurology, 68:1902-8.

Tanzi RE, Bertram L. 2005. Twenty years of the Alzheimer's disease amyloid hypothesis: a genetic perspective. Cell, 120:545-55.

Thal DR, Ghebremedhin E, Orantes M, et al. 2003. Vascular pathology in Alzheimer disease: correlation of cerebral amyloid angiopathy and arteriosclerosis/lipohyalinosis with cognitive decline. J Neuropathol Exp Neurol, 62:1287-301.

Theuns J, Brouwers N, Engelborghs S, et al. 2006. Promoter mutations that increase amyloid precursor-protein expression are associated with Alzheimer disease. Am J Hum Genet, 78:936-46.

Tobinick E, Gross H, Weinberger A, et al. 2006. TNF-alpha modulation for treatment of Alzheimer's disease: a 6-month pilot study. MedGenMed, 8:25.

Tobinick EL, Gross H. 2008. Rapid cognitive improvement in Alzheimer's disease following perispinal etanercept administration. $J$ Neuroinflammation, 5:2.

Tobiume K, Matsuzawa A, Takahashi T, et al. 2001. ASK1 is required for sustained activations of JNK/p38 MAP kinases and apoptosis. EMBO Rep, 2:222-8.

Tomlinson BE, Blessed G, Roth M. 1970. Observations on the brains of demented old people. J Neurol Sci, 11:205-42. van der Wal EA, Gomez-Pinilla F, Cotman CW. 1993. Transforming growth factor-beta 1 is in plaques in Alzheimer and Down pathologies. Neuroreport, 4:69-72.

Varfolomeev EE, Ashkenazi A. 2004. Tumor necrosis factor: an apoptosis JuNKie? Cell, 116:491-7.

Vietor I, Schwenger P, Li W, et al. 1993. Tumor necrosis factor-induced activation and increased tyrosine phosphorylation of mitogenactivated protein (MAP) kinase in human fibroblasts. $J$ Biol Chem, 268:18994-9.

Wajant H, Pfizenmaier K, Scheurich P. 2003. Tumor necrosis factor signaling. Cell Death Differ, 10:45-65.

Whalen BM, Selkoe DJ, Hartley DM. 2005. Small non-fibrillar assemblies of amyloid beta-protein bearing the Arctic mutation induce rapid neuritic degeneration. Neurobiol Dis, 20:254-266.

Whitehouse PJ, Price DL, Struble RG, et al. 1982. Alzheimer's disease and senile dementia: loss of neurons in the basal forebrain. Science, 215:1237-9.

Wisniewski HM, Wegiel J. 1995. The neuropathology of Alzheimer's disease. Neuroimaging Clin N Am, 5:45-57.

Wong GH, Goeddel DV. 1988. Induction of manganous superoxide dismutase by tumor necrosis factor: possible protective mechanism. Science, 242:941-4.

Wyss-Coray T, Masliah E, Mallory M, et al. 1997. Amyloidogenic role of cytokine TGF-beta1 in transgenic mice and in Alzheimer's disease. Nature, 389:603-6. 
